of space as the Isle of Man to the whole surface of the earth. Reference was then made to the conclusions of Friedmann and Lemaître that the equilibrium of such a universe would be unstable, and if expansion started it would continue. Sir James conjectures that the initial impulse which started the expansion may have arisen in the process of the condensation of the primeval chaotic gases into nebulæ. Spectrograms of the distant galaxies indicate such an expansion, the rate of recession being about 105 miles per second at a distance of a million light-years, and increasing in the same proportion as the distance, so that it attains the amount of 15,000 miles per second for the most distant nebula yet measured.

Aluusion was then made to the difficulty of reconciling this rapid recession with a past duration of the universe extending to millions of millions of years. Sir James has himself given strong reasons in favour of such a past duration, but he now admits that it may be necessary to abandon it. There are, however, some alternatives; there might have been a long period before the recession got fairly started; or the spectral shift that appears to indicate recession may be due to some other cause. Allusion was made to Sir Arthur Eddington's attempt to evaluate the cosmical constant, and so obtain a theoretical value for the rate of expansion; he obtained a value quite close to the observed rate. Sir James noted that this result, while intensely interesting as linking up the largest and the smallest objects of observation, is still a matter of controversy, and cannot be accepted as certain.

\section{Hughlings Jackson Memorial Medal}

Dr. Hugruings JAckson, who died in 1911, gave the first Hughlings Jackson lecture that was founded in 1897 in his honour by the Neurological Society of London. With a few intervals, as during the War, this lecture has been given triennially, by an eminent neurologist or physiologist. Last year the Section of Neurology of the Royal Society of Medicine decided to form a fund to endow the lectureship with a gold medal and an honorarium of a hundred guineas triennially, and subscriptions were invited by a committee of which Mr. Leslie Paton was chairman and Dr. Wilfred Harris treasurer ; 146 subscribers from many parts of the world produced a sum of just over $£ 1200$, which has been handed over to the Royal Society of Medicine, after paying for the design of a gold medal by Mr. Percy Metcalfe, the work being carried out by the Royal Mint. Sir Charles Sherrington, who gave the last lecture, on "Quantitative Management of Contraction in Lowest Level Co-ordination ", has been awarded the first medal.

THe first Hughlings Jackson Memorial Medal, with the honorarium, was formally presented to Sir Charles Sherrington on Thursday, May 19, by Dr. Watts Eden, president of the Royal Society of Medicine. Before doing so, Dr. Stanley Barnes, president of the Section of Neurology, introduced Sir Charles Sherrington as an original member of the Neurological Society in 1886, and referred to Sir Charles's fame as an experi- menter. He also called upon another original member of the Society who was present, Sir James CrichtonBrowne, to give some personal recollections of Hughlings Jackson. Sir James recalled that in the early 'seventies Jackson had regularly visited the West Riding Asylum at Wakefield, where Sir James was then medical superintendent, and contributed several articles to their reports. After Sir James left Wakefield for London, he, with Hughlings Jackson, Ferrier, and Bucknill, founded the neurological journal, Brain. After Sir Charles Sherrington's reply, thanking the Royal Society of Medicine and the Fund Committee for their valuable prize, Mr. Leslie Paton presented Dr. Watts Eden, for the Royal Society of Medicine, with two replicas of the Jackson Medal, in toned silver, suitably framed.

\section{Two-way Television}

WHEN the possibility of television was recognised, the first application that suggested itself was to show the image of a person hundreds of miles away. A natural development was to superpose a television on a telephone system so that the hearer could both see the speaker and hear him talking. This latter method is used daily by the B.B.C. in the television radio broadcasts. A successful experiment showing the combination of ordinary telephony with two-way television was demonstrated to the Press in Paris on May 19, and an account of it appeared in the Times on the following day. The television apparatus used was supplied by the Baird Television Corporation. Infra-red rays are obtained by filtering artificial light through ebonite screens. They fall on both the speaker and the hearer. Only invisible rays are used to produce the electrical impulses in the connecting wires. At the ends of the line they are converted into light rays and focused on screens. It is difficult for either the speaker or listener to realise that his head and shoulders are in full view of the other. The visual screens are ten inches long by five inches broad. As the scanning disks make $\mathbf{7 5 0}$ revolutions per minute, $12 \frac{1}{2}$ complete images per second appear on the visual screen. At this speed there is little flickering. The features are easily recognisable and the play of expression on the face is remarkably clear. The movement of the lips can easily be followed. If necessary, the 'fineness' of the images could be improved by increasing the number of dots. In the near future, public communication combined with television on a commercial basis will be started between Paris and Lyons. The Baird-Nathan Company is exploiting this system in France, and later on it is hoped to connect Paris and London in this way. A form of two-way television was demonstrated in New York by the Bell Telephone Co. on April 9, 1930 (Nature, May 31, 1930).

\section{London Power Supply}

Tнस Central Electricity Board was created by the Act of 1926, and was given great powers to co-ordinate generation throughout the whole of Great Britain, including the London area. In 1929-30 the load for this area, excluding the railway and tramway re- 
quirements, was supplied by 58 generating stations. Of these stations, 27 small ones supplied only four per cent of the total load, the average generating cost per unit being more than $\mathbf{1} \cdot \mathbf{5} d$. Five groups of large stations supplied 66 per cent of the total load, the average generating costs being $0 \cdot \mathbf{4} 66 d$. per unit. When the extensions at Barking and the new stations at Battersea and Fulham come into operation, even better results will be obtained by the larger stations. The fundamental geographical feature from the point of view of electrical generation is the Thames Valley, with its abundant supply of water for condensation purposes and its facilities for the transport of waterborne coal. In a lecture by J. D. Peattie, published in the Electrician for May 6, an account is given of the interconnexion of the generating stations in the London area. Within a radius of ten miles from Charing Cross, there are now hundreds of lattice towers supporting stranded cables for the grid at 132 kilovolts and for connecting stations at 66 and $33 \mathrm{kv}$. There is a notable river crossing between Barking and Northfleet, where two towers, 487 feet high, will give a clearance under the wires at high water of $250 \mathrm{ft}$. on a span of $3060 \mathrm{ft}$. These towers are the highest on the grid and will carry two double circuits. They are specially painted, and will be illuminated at night to give warning to aircraft flying along the Thames Valley. On the way to Southend one of them is now a conspicuous landmark.

\section{The Hannah Dairy Research Institute}

A BRIEF account of the researches already carried out at the recently established Hannah Dairy Research Institute, Kirkhill, Ayr, is given by the director, Dr. N. C. Wright, in the Ayrshire Cattle Society's Journal, vol. 3, No. 1. An investigation into the incidence of certain bovine diseases, especially tuberculosis and milk fever, has been commenced, and, as a result, recommendations have been made which should lead to the elimination from tested herds of a large proportion of the animals reacting positively to the tuberculin test. Inquiry is also being made into the length of life of milking cows in Scottish herds and into the main causes which lead to the unremunerative disposal of stock. The problems of the utilisation of surplus milk and of milk by-products also received attention. Investigations on the biological side require laboratory accommodation, which has only recently become adequate with the completion of the buildings at Kirkhill. They will include a re-investigation of the protein requirements of dairy cows, and an investigation of the physiology of lactation. In addition, the problems involved in improvement of the dairy stock by selective inbreeding and in the methods used in condensing and drying milk, sepa. rated milk, and whey will be examined. Two-thirds of the income of the Institute is received in the form of a grant from the Development Commissioners, but the remaining third must be raised from non-government sources. It is estimated that $£ 2000$ will be required annually, and it is hoped to secure an endowment fund which will supply an assured income of this order.

No. 3265, VoL. 129]

\section{Anthropological Bibliography}

ANTHROPOLOGY in particular among the sciences is not well served in the matter of indices and bibliographies, though what is needed is, perhaps, co-operation rather than extended effort. There is already in existence a number of bibliographies dealing each with some one or more departments of anthropological science. Some of these overlap, and none can be called really complete. The latest of these has been compiled by M. Joseph Nippgen, librarian of the Société de Géographie of Paris, and has appeared in L'Ethnographie ; it may be obtained separately from the Société d'Ethnographie de Paris. It covers contributions to general and comparative ethnology, and folklore and comparative religion, while ethnographical papers and books dealing with specific geographical areas are grouped under continents. A few items in archæology and physical anthropology are included. This bibliography has the additional advantage that a considerable number of the items are analysed at some length by the compiler. There is, unfortunately, no indication of the period of publication covered by the compilation as a whole, though the latest date appearing is 1929 . The current issue of L'Anthropologie (T. 40, Nos. 5-6) is devoted entirely to an index of vol. 21-40 of that periodical, issued for the years 1910-31. The index is divided into two parts, of which the first contains a list of authors in alphabetical order and the second is a subject index. Titles of original communications and variétés are distinguished from book reviews by a difference in type; but no distinction is made between the names of authors of books reviewed and of original communications. In consequence, the arrangement gives undue prominence to what, from the point of view of most who will wish to consult L'Anthropologie, must be regarded as much in the nature of second-class matter. Notwithstanding this inconvenience, the index is a great boon, and an example that might well be followed with advantage by many more of the British scientific periodicals which have a long run.

\section{New Mayan Site in Yucatan}

A RUINED Mayan city of enormous proportions, previously unknown, has been discovered in southern Yucatan by Mr. C. L. Lundell, a representative of the American Chicle Development Company. The ruins are situated in the south-east corner of Campeche and are difficult of access ; but under an arrangement with the Mexican Government they have been inspected by Dr. Sylvanus G. Morley, accompanied by a party of five. The city has been named Calakmul, "The Two Adjacent Hills", by its discoverer. In Dr. Morley's report, as circulated by Science Service, of Washington, D.C., the site is said to contain many more sculptured monuments than any Mayan city hitherto known. There are no less than one hundred and three stelæ with sculptured figures and hieroglyphs. Some of the stelæ are of high artistic merit. Fifty-one are dated, and one-half of these have been deciphered. It is evident that the city was once a 